
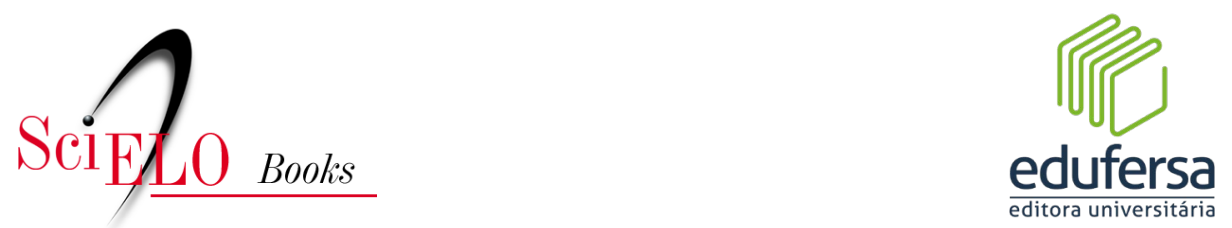

\title{
Parte I - Cultura e Cidadania 1 - Etnoturismo potiguar: possibilidade sustentável de geração de renda em comunidades indígenas
}

Jacqueline Cunha de Vasconcelos

\section{Martins}

Edson Vicente da Silva
Alan Martins de Oliveira

Tayse Michelle Campos da Silva

\section{SciELO Books / SciELO Livros / SciELO Libros}

MARTINS, J. C. V., OLIVEIRA, A. M. , SILVA, E. V., SILVA, T. M. .C, and OLIVEIRA, I. P. R. A. Etnoturismo potiguar: possibilidade sustentável de geração de renda em comunidades indígenas. In: OLIVEIRA, A. M., SILVA, L. R., and FALCÃO, M. L., eds. Sociedade e cultura no Rio Grande do Norte: diálogos interdisciplinares [online]. Mossoró: EdUFERSA, 2021, pp. 13-36. ISBN: 978-65-87108-24-7. https://doi.org/10.7476/9786587108582.0002.

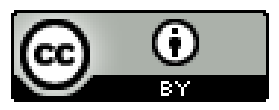

All the contents of this work, except where otherwise noted, is licensed under a Creative Commons Attribution 4.0 International license.

Todo o conteúdo deste trabalho, exceto quando houver ressalva, é publicado sob a licença Creative Commons Atribição 4.0.

Todo el contenido de esta obra, excepto donde se indique lo contrario, está bajo 


\section{ETNOTURISMO POTIGUAR: POSSIBILIDADE SUSTENTÁVEL DE GERAÇÃO DE RENDA EM COMUNIDADES INDÍGENAS}

Jacqueline Cunha de Vasconcelos Martins

Alan Martins de Oliveira

Edson Vicente da Silva

Tayse Michelle Campos da Silva

Ingride Pamilly Ribeiro Araújo de Oliveira

Caboclos da minha terra, peço vossa inspiração, para contar a história dos índios do meu Sertão, que tinham muita coragem, mas foram postos à margem pelas forças da opressão.

Na roda-viva do tempo, já foram donos de tudo: serra, várzea e tabuleiro, bicho pequeno e graúdo; o que deixaram, de herança, pouco resta, na lembrança, quase tudo ficou mudo.

A Ribeira do Açu, há muitos tempos atrás, era habitada por índios, nossos bravos ancestrais, perambulando na terra, desde a várzea até a serra, no meio dos catingais [...]

Extraído do Cordel "Índios do Rio Açu" (MELO, 2013) 


\subsection{Considerações iniciais}

Os povos nativos do Brasil com sua ampla diversidade cultural, tradições, línguas e crenças, passaram a ser chamados genericamente de "índios" pelos agentes externos, os invasores. Durante o processo de colonização, vários fatores como morticínios, aculturação e outras imposições territoriais, sociais e econômicas sobre as populações etnicamente diferenciadas impactaram nas evidentes mudanças socioculturais dessas populações, sobretudo na Região Nordeste e em toda extensão do litoral brasileiro.

Não é possível reconhecer qualquer forma de organização indígena quando nem mesmo se reconhece a existência desses povos. Afinal, fatores como a memória e o sentimento de pertença ao seu povo, à sua terra e à sua história identificam um povo indígena. No caso do Nordeste, frequentemente os indígenas são chamados de miscigenados, remanescentes, descendentes de índios ou aculturados, o que carrega o peso da insegurança da sociedade, do poder público e até de pesquisadores em falar sobre estes com a força da autoafirmação.

Estudos críticos apontam sobre o "desaparecimento" indígena no Rio Grande do Norte reforçado na historiografia clássica (MACEDO, 2011). Todavia, nova realidade tem se configurado à medida que os povos indígenas vêm ocupando espaços em organismos internacionais, a exemplo dos documentos que destacam o direito à livre determinação ou autoidentidade (ONU, 2007; OIT, 2011).

Organizações como o Conselho Indigenista Missionário - CIMI (2011), que reforça sobre a reivindicação por demarcação de Terras Indígenas - TIs no Rio Grande do Norte desde 2005 e a Associação Nacional dos Povos Indigenistas - ANAí (2020), que faz o acompanhamento da situação fundiária, destacam a existência destes povos em terras potiguares ${ }^{1}$. Também corroboram sobre a presença indígena pesquisas históricas e antropológicas desenvolvidas nos programas

1 Quem nasce no Rio Grande do Norte é chamado de potiguar ou norte-riograndense. Potiguar", de origem tupi, significa comedor de camarãoc e designava os potiguaras, habitantes originários da região (MONTEIRO, 2015). 
de pós-graduação das universidades públicas regionais, a exemplo de estudos sobre os Mendonça do Amarelão (GUERRA, 2017; CAMPOS, 2014) e sobre os Caboclos do Assu (OLIVEIRA, 2014), localizados respectivamente nos municípios de João Câmara e Assu.

Segundo Oliveira (1998, p. 51): "é a partir de fatos de natureza política — demandas quanto à terra e assistência formuladas ao órgão indigenista - que os atuais povos indígenas do Nordeste são colocados como objeto de atenção para os antropólogos sediados nas universidades da região".

Em 2005, marco da mobilização no Estado, três comunidades se autoidentificaram indígenas em audiência pública na Assembleia Legislativa do Rio Grande do Norte: Mendonça do Amarelão, Caboclos do Assu e Eleotérios do Catu, (VIEIRA; KÓS, 2017). Em estudo sobre os Tapuia-Paiacú na zona urbana de Apodi-RN, Freitas (2018) afirma que a partir do autorreconhecimento têm surgido diversas comunidades-estado indígenas. Dessas, quatro formalizaram o relatório de Qualificação de Reinvindicação de Demarcação de Terras através de registro no Departamento de Proteção Territorial-DPT da FUNAI: Caboclos do Assu (Assu), Amarelão (João Câmara), Tapará (Macaíba) e Catu (Canguaretama). Em 2015, atendendo à recomendação do Ministério Público Federal e da Advocacia Geral da União, a Fundação Nacional do Índio - FUNAI instituiu um Grupo Técnico - GT para identificar e delimitar a TI de uma das comunidades, em decorrência de conflitos fundiários (VIEIRA; KÓS, 2017; BRASIL, 2019).

Conforme o CIMI (2016), os mapas oficiais representam 36,7\% dos territórios indígenas do Brasil, uma vez que consideram apenas as terras indígenas demarcadas ou em processo de demarcação, a exemplo dos disponíveis pela FUNAI (BRASIL, 2020). Segundo dados do Instituto Brasileiro de Geografia e Estatística (IBGE, 2010), a população indígena no Rio Grande do Norte passou de 394 em 1991 para 3.168 em 2000 e decresceu em 2010 para 2.597. Porém, como ilustração de que o censo oficial subestima essa população no Estado, enquanto nos dados do IBGE há registro de apenas 324 pessoas no Amarelão, no censo comunitário local 966 pessoas se autodeclararam indígenas (ACA, 2018). 
Considerando esta incoerência, um representante do IBGE foi convidado a prestar esclarecimentos durante a II Assembleia dos Povos Indígenas do Rio Grande do Norte, que aconteceu em 2011 no município de Goianinha-RN. Na ocasião, lideranças indígenas afirmaram que o número reduzido das populações no censo oficial foi reflexo de falha metodológica dos recenseadores na aplicação do questionário, uma vez que frequentemente omitiram a pergunta sobre raça-cor, impactando em dados estatísticos que não refletem a realidade. Vale reforçar que tal fato não se configurou em negação de identidade pelos próprios indígenas. Como encaminhamento, foi proposto ao citado representante a capacitação adequada aos recenseadores quanto à autodeclaração étnica.

A busca ainda pelo reconhecimento e a luta pela tardia demarcação das terras aliados à insuficiência de políticas públicas interferem fortemente na sustentabilidade e preservação sociocultural, ambiental e econômica desses povos. A Agenda 2030, elaborada pela Organização das Nações Unidas - ONU (2015), prevê ações que promovam a sustentabilidade por meio dos 17 Objetivos do Desenvolvimento Sustentável - ODS, dentre os quais estão contemplados aspectos relacionados à melhoria da qualidade de vida e reconhecimento dos direitos dos povos indígenas, bem como a sustentabilidade social, ambiental e econômica.

Boff (2012) afirma que o caminho da sustentabilidade deve partir do local, respeitando os ecossistemas com suas diversas formas de vida, viabilizando o desenvolvimento e priorizando o ser humano em detrimento do capital. Para tanto, é necessário planejamento em uma abordagem sistêmica (CAPRA, 2001; RODRIGUEZ; SILVA; CAVALCANTI, 2013), visando passar de um modelo econômico predatório de "crescimento" para um estado de economia constante (SACHS, 2012). Portanto, é necessário aliar reconhecimento e efetivação de direitos com sustentabilidade dos povos indígenas. Nesse cenário surge o etnoturismo, que é uma categoria de turismo cultural, de base comunitária, como possibilidade de geração de renda.

O turismo cultural é aquele que visa conhecer e divulgar os bens materiais e das culturas imateriais locais. Assim, o etnoturismo se configura em um tipo turismo cultural, pois utiliza como atrativos 
os aspectos culturais de um determinado grupo étnico, por exemplo, imigrantes de um país, quilombolas, ciganos e indígenas (FARIA, 2005). Por sua vez, González (2008), embora corrobore que etnoturismo indígena está associado aos aspectos culturais em todas suas expressões sociais e produtivas cotidianas, categoriza como um tipo de turismo rural e também como alternativo.

Diante do exposto, o objetivo deste capítulo é apresentar as potencialidades etnoturísticas em duas comunidades autoidentificadas indígenas no Rio Grande do Norte, destacando aspectos socioambientais e culturais, como alternativas viáveis de geração de renda.

$\mathrm{Na}$ metodologia qualitativa adotada (MINAYO, 2016), as informações apresentadas sobre as comunidades autoidentificadas indígenas Mendonça do Amarelão e Caboclos do Assu, localizadas respectivamente nos municípios potiguares de João Câmara e Assu, foram obtidas através de observações in loco, registro fotográfico, diálogo informal com moradores e entrevistas abertas com lideranças sobre aspectos sociais, econômicos, culturais e potencialidades turísticas. As lideranças entrevistadas formalmente estão devidamente citadas nas referências, enquanto os depoimentos obtidos informalmente estão expostos de forma anônima de modo a preservar as identidades.

\subsection{Valorização local e geração de renda}

No ambiente rural brasileiro, os modelos convencionais de produção não se aplicam de forma sustentável em comunidades tradicionais ou familiares e notadamente nas indígenas. Isso é particularmente importante nas regiões com escassez de água como o semiárido brasileiro, com efeito direto na capacidade de produção agrícola e pecuária que implica na necessidade de buscar outras fontes de renda.

Daí a necessidade de adaptação de novas tecnologias e ideias associadas à valorização local, em que as atividades não agrícolas podem ser de grande impacto positivo na geração de renda (SOUZA et al., 2011). Uma destas possibilidades é o etnoturismo, como fonte de renda viável para as comunidades indígenas existentes no Rio Grande do 
Norte, além do desenvolvimento de outras atividades econômicas não associadas à produção agrícola e pecuária, a exemplo do artesanato e da agroindustrialização.

A literatura internacional, segundo Pereiro (2013), aponta três perspectivas na realidade da América Latina em relação ao turismo em comunidades indígenas: otimista, pessimista e adaptativa. Na perspectiva otimista, é quando a comunidade se empodera da atividade de tal forma que efetivamente se beneficia, inclusive financeiramente, e o gerenciamento não sofre intervenção predatória de terceiros. $\mathrm{Na}$ perspectiva pessimista, devido aos impactos negativos do turismo nas comunidades, questionam-se os reais benefícios, uma vez que as vantagens ficam para as empresas intermediárias de turismo. $\mathrm{Na}$ perspectiva apontada como adaptativa, os efeitos positivos e negativos são avaliados de acordo com o contexto local. Nesse caso, a gestão indígena do etnoturismo mantém o controle sobre seus bens naturais e culturais com autonomia inclusive para "dizer não".

É necessário atentar aos impactos da "espetacularização" da cultura indígena, que, de origem nativa, não pode ser tratada como "exótica", quer seja por agentes públicos ou privados. Logo, as visitações nessas comunidades devem ser feitas de forma respeitosa por pesquisadores, sociedade civil, indústria cultural, empresas de turismo e de publicidade (CARVALHO, 2010).

No Brasil, o Decreto ${ }^{\circ}$ 7.747/2012, que instituiu a Política Nacional de Gestão Territorial e Ambiental de Terras Indígenas (PNGATI), determina no eixo sobre o uso sustentável de recursos naturais e iniciativas produtivas indígenas um item específico sobre o etnoturismo e ecoturismo que enfatiza o respeito à decisão da comunidade. Desse modo, o decreto possibilita que as autoridades ambientais exijam diagnósticos de impactos socioambientais e que sejam realizadas capacitações das comunidades para a gestão intrínseca das ações de turismo.

A Instrução Normativa 03/2015 da FUNAI (BRASIL, 2015) estabelece normas para a visitação com fins turísticos em TIs, de base comunitária e sustentável, nos segmentos de etnoturismo e de ecoturismo. Esse documento é um avanço quanto ao papel das empresas de turismo, uma vez que determina a apresentação à FUNAI de um de plano de 
visitação e monitoramento e exige também o registro para as autoridades de qualquer ocorrência de incidentes ou procedimentos ilícitos, com ênfase em possíveis impactos ambientais das atividades turísticas.

As populações tradicionais têm categorias próprias para nomear e classificar o ambiente e, por conviverem com a biodiversidade, não enxergam como um recurso natural, apenas com valor de uso, mas como seres vivos que têm também valor simbólico (SILVA et al., 2016). Em estudo sobre a relação entre turismo e desenvolvimento local desenvolvido na reserva do Tupé, Estado do Amazonas, foi verificado que o turismo preservacionista pode ser uma fonte de retroalimentação da preservação da natureza e dos costumes indígenas. Conforme um representante indígena da citada reserva, "[o turismo] faz com que os povos indígenas entendam melhor a preservar a natureza" (FURTUNATO; SILVA, 2011, p. 15).

Todavia, em estudo de caso sobre as unidades de paisagem na TI em Itapipoca, Ceará, o potencial turístico é apontado com risco de exploração predatória e é feito o alerta para a necessidade de demarcação das terras, a fim de orientar adequadamente as formas de uso, ocupação de solo e desenvolvimento de atividades não agrícolas, fornecendo suporte para a preservação física e cultural daquele grupo étnico (MEIRELES, 2011).

No Rio Grande do Norte, atividades ligadas ao etnoturismo ainda são incipientes. Félix et al. (2020) em estudo sobre os aspectos do etnoturismo em comunidades autodeclaradas indígenas e quilombolas nesse Estado verificaram que as ações e o apoio do poder público são insuficientes para o desenvolvimento desta atividade econômica. Assim, sugerem a participação da comunidade receptora nas decisões sobre o turismo, de modo a estimular a autonomia e empoderamento, além de proporem, entre outras coisas, a gestão participativa, elaboração de leis municipais em prol da conservação do patrimônio cultural e ambiental e a criação de espaços de representação e exposição das culturas tradicionais como museus, memoriais e casas de artesanato. Os autores também sugerem o incentivo ao turismo sustentável, envolvendo a capacitação dos atores locais com apoio do poder público. 
Neste capítulo, a ênfase é para duas comunidades indígenas, Mendonça do Amarelão e Caboclos do Assu, localizadas nos municípios em destaque na Figura 1.

Figura 1-Cidades do Rio Grande do Norte onde estão localizadas as Comunidades

Caboclos do Assu e Mendonça do Amarelão

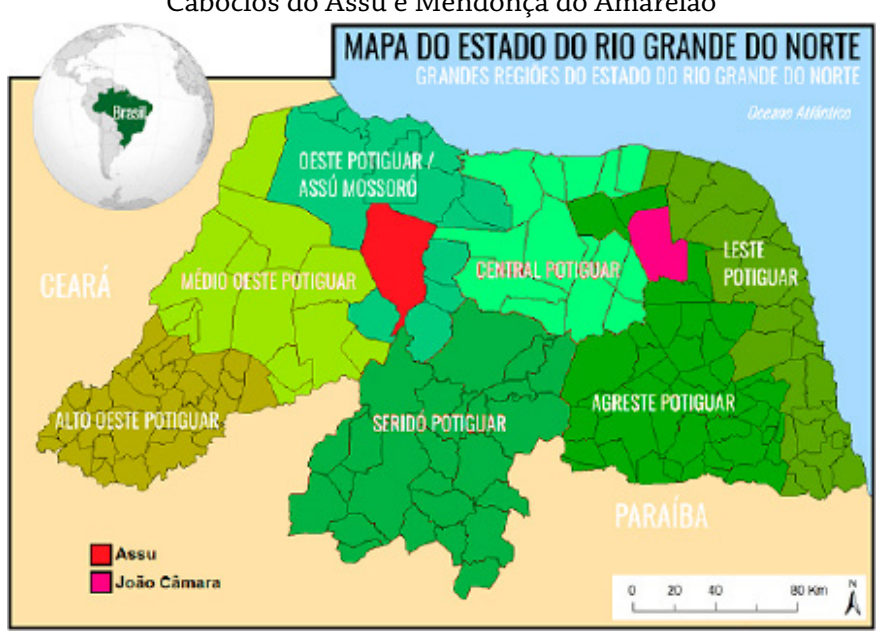

Fonte: Adaptado de IBGE (2017) e Open Brasil (2017).

\subsection{Comunidade Mendonça do Amarelão}

A Comunidade Mendonça do Amarelão, localizada na região do Mato Grande, na zona rural de João Câmara-RN, fica a $14 \mathrm{~km}$ da sede do município, sendo a $10 \mathrm{~km}$ na BR 406 e $4 \mathrm{~km}$ de estrada de terra (GUERRA, 2017). Segundo censo comunitário local realizado pela associação, a população local é de 966 pessoas, sendo 287 famílias que habitam em quinze agrupamentos ou setores familiares (ACA, 2018). Tem vegetação predominante de caatinga, jurema, marmeleiro, cactos e bromélias, entre outras; e os animais mais presentes são camaleões, tatu, peba, preá, raposa, veado, além de vários tipos de aves (SILVA, 2017). 
A principal fonte de geração de renda local é o beneficiamento da castanha de caju. Através desta atividade familiar, a comunidade passou à autossustentação como forma de permanecer em seu território. Além de alternativa de sobrevivência, é uma forma de garantia da permanência da família no seu lugar de origem e é regida pelo forte sentimento de pertença do grupo e de sua relação com a terra. Os locais de beneficiamento são barracas construídas nos quintais das casas, principalmente pelo fato de possibilitar às mulheres conciliar o trabalho com as atividades domésticas e cuidados com os filhos.

A comunidade é a maior beneficiadora de castanha do Rio Grande do Norte e a comercialização é feita em João Câmara, em Natal e em outros estados. Também desenvolvem artesanato e produzem na cozinha da Associação Comunitária do Amarelão - ACA derivados da castanha como bolos, cocadas e farinha de castanha. A comercialização destes produtos é feita na própria associação e em João Câmara (SILVA, 2017).

$\mathrm{Na}$ agricultura familiar são cultivados milho, feijão, batata doce, jerimum, melancia, umbu, entre outros produtos. Na pecuária, alguns criam animais de pequeno porte para consumo próprio e comercialização do leite de vaca e esterco. Na gastronomia local, além dos produtos mencionados, incluem a mandioca e seus derivados, como tapioca e beiju (SILVA, 2017).

Somente um pequeno número de pessoas trabalha fora da comunidade, sendo, em grande parte, homens com baixo grau de instrução formal que trabalham predominantemente na construção civil. Entretanto, a maioria dos indígenas com formação acadêmica mora e atua na própria comunidade.

$\mathrm{Na}$ infraestrutura local convém destacar a associação e cozinha comunitárias, o posto de atendimento médico, a quadra esportiva, uma escola municipal de ensino fundamental e, em especial, a escola de ensino médio "Escola Estadual Indígena Professor Francisco Silva do Nascimento", considerada a melhor do município em infraestrutura, com professores da própria comunidade. Inaugurada em 2019, atende o território indígena Mendonça, que abrange as comunidades Amarelão, Serrote de São Bento, Açucena, Assentamento Santa Terezinha e Assentamento Marajó. Seu projeto original, idealizado 
pela Irmã Terezinha Galles, católica que atuou na comunidade, e pelas professoras do Amarelão, Maria Ivoneide Santos Silva e Francisca Batista (Dona Chiquinha), foi entregue à Secretaria de Educação do Estado em 2005 e sua construção iniciada em 2018, como resultado das reivindicações da comunidade e da parceria entre o Governo do Estado e Banco Mundial.

A Família extensa Mendonça do Amarelão é de etnia potiguara, de origem dos índios "Tapuia", falantes do tupi e também ocupa outros espaços territoriais já citados. A denominação "Amarelão" se deve ao ritual de culto ao sol, celebrado por seus antepassados (GUERRA, 2017; SILVA, 2017).

\subsection{Atrativos naturais e socioculturais}

É relevante para o desenvolvimento de atividades etnoturísticas a preservação dos costumes indígenas locais. No Amarelão, dentre os atrativos naturais e culturais preservados, são considerados importantes locais reconhecidos pelos nativos como "pontos de memória". Estes ambientes podem ser traduzidos sob o olhar de Nora (1993) como "lugar de memória", ou seja, aqueles ambientes naturais ou construídos por obra humana, que têm relação com a intimidade de memória para reconstituir o olhar das pessoas a respeito daquele espaço, quer por razões afetivas, culturais, sociais ou místicas.

Destes pontos, merecem destaque: a pedra das letras, com registro de escritas rupestres dos primeiros povos que habitaram a região; a gameleira, uma árvore com mais de dois séculos, embaixo da qual era realizada a feira para troca e compra de produtos da pesca, caça e agricultura; a pedra do sino, que ecoa um som semelhante ao de sino quando alguém bate com um seixo; e os tanques de pedra, lajedo com fendas formadas naturalmente que em seu entorno corre um riacho no período das chuvas, também utilizado como espaço de lazer.

Dentre os locais antigos, têm destaque uma casa de taipa, construída há mais de 70 anos, e a cacimba salgada, local que marca a divisão social de territórios nas comunidades. Além de outros atrativos 
naturais e culturais, que inclui uma trilha ecológica de $4 \mathrm{~km}$ com alguns dos pontos de memória citados.

Um aspecto marcante da cultura dessa etnia é o toré, dança indígena potiguara (Figura 3), na qual glorificam a mãe natureza e expressam seus sentimentos aos antepassados, além do resgate da Língua Tupi de seus ancestrais.

Figura 3-Ritual do Toré

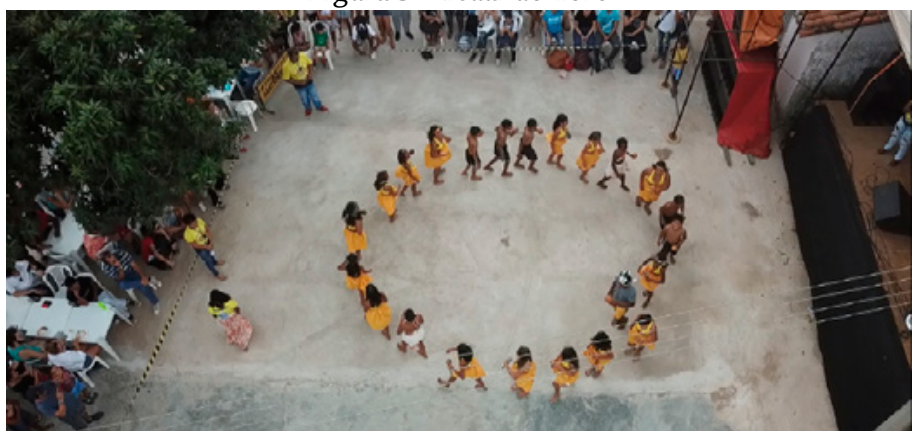

Fonte: Martins (2019).

$\mathrm{Na}$ atual escola de ensino fundamental é ensinada a Língua Tupi e a dança do toré, visando preservar a cultura indígena. Segundo informa uma liderança, a comunidade inseriu o ensino tupi no currículo da escola local de $1^{\circ}$ ao $5^{\circ}$ ano, de modo que "as crianças já cantam os cantos do toré em tupi” (SILVA, 2017). Segundo o ISA (2017, p. 1), na maioria dos grupos indígenas do Nordeste:

O toré é uma importante prática ritual, capaz de balizar as diferenças internas, projetando os grupos nas situações de contato. No caso dos Potiguara, o toré é geralmente realizado nas comemorações do Dia do Índio (19 de abril), sendo pensado como um "ritual sagrado" que celebra a amizade entre as distintas aldeias, realçando o sentimento de grupo e de nação. É uma dança que está na própria percepção e representação da tradição coletiva, sendo, portanto, um elemento essencial para eles se pensarem enquanto possuidores de um passado histórico comum. 
Outro atrativo cultural e relevante ponto de memória é a linha férrea, considerada marco divisor das comunidades indígenas Amarelão e Assentamento Santa Terezinha, que antigamente era o único acesso ao município da cidade Baixa Verde, atualmente João Câmara. As famílias Mendonça saíam das comunidades para o município a pé, toda semana, para fazer compras ou iam buscar carro para socorrer alguém doente ou mulher grávida, cujo parto fosse inviável pelas parteiras da comunidade.

A Festa da Castanha (Figura 2) é uma atividade cultural promovida anualmente pela ACA, juntamente com a comunidade local e o apoio de parceiros. Essa festa começou a ser realizada na década de 1990 pelo primeiro presidente da ACA, como uma atividade de lazer. Em 2012, ganhou novo formato, com os objetivos de valorizar o trabalho desenvolvido na comunidade pelo fortalecimento da cadeia produtiva da castanha e promover o escoamento dos produtos locais, dando maior visibilidade e fortalecimento à identidade etnocultural dos Mendonças do Amarelão. A tradição se dá anualmente no último sábado de agosto, atraindo visitantes regionais, de outros estados e até estrangeiros em passagem pelo Estado.

\section{Figura 2-Festa da Castanha}

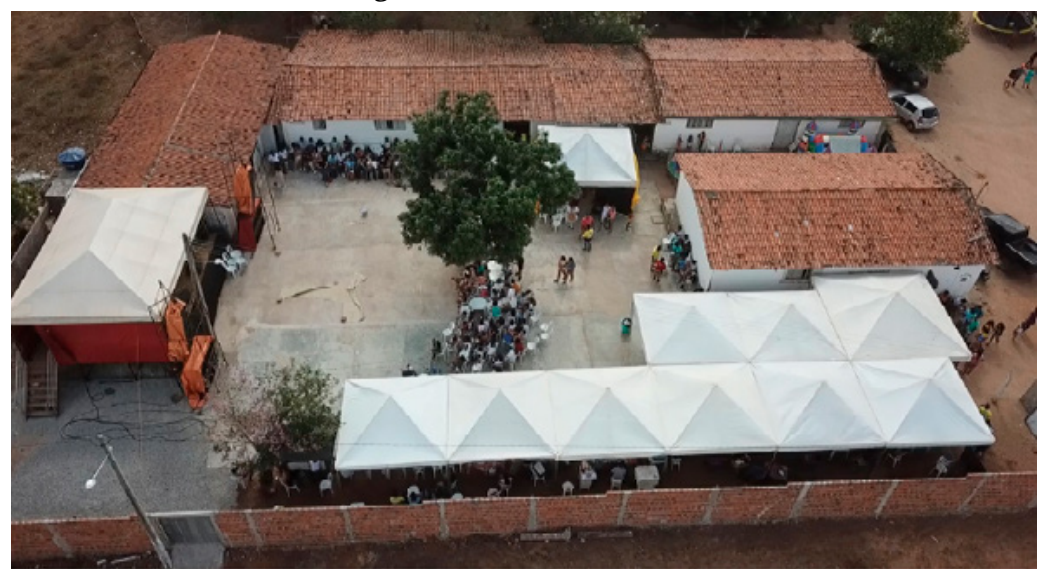

Fonte: MARTINS (2019). 
O evento é bem diversificado e atrativo com exposição e comercialização de tudo o que é produzido a partir da castanha, além dos artesanatos locais. Há ainda exposição de fotos e palestras sobre o povo indígena Mendonça do Amarelão e o processo de beneficiamento da castanha de caju; trilhas para visitação aos pontos de memória com escritas rupestres e o tanque de pedra; apresentações culturais como o toré, a banda de flauta e a orquestra Irmã Terezinha Galles, formada por crianças e jovens indígenas. É realizado ainda um almoço comunitário, além de jogos, brincadeiras, apresentações artísticas teatrais e de grupos musicais.

Sobre os produtos comercializados, podem ser destacados: a própria amêndoa nas opções torrada, natural, com sal e caramelizada; as comidas típicas feitas com a castanha como arroz, farofa, cocada, bolo, pavê e brigadeiro; no artesanato indígena tem cocar, maracá, móbile, filtro dos sonhos, colares, pulseiras, anéis de coco, brincos, tererê e tiara, entre outros.

Em relação à capacidade para recepcionar grupos, segundo a liderança indígena, a comunidade tem experiência em receber professores, estudantes e intercâmbios entre comunidades, grupo de jovens etc. "Já servimos até 300 almoços e três refeições ao dia para 150 pessoas, numa conferência realizada na comunidade durante três dias". Porém, destaca: "não temos experiência com turistas" (SILVA, 2017).

Assim, o etnoturismo apresenta expressivo potencial na Comunidade Amarelão. Além de contribuir para o resgate da memória e preservação cultural, propicia trabalho e renda. Quando realizado de forma sustentável, é uma ação de resistência, com viés educativo e disseminador ao propiciar a troca de conhecimentos e a desconstrução de estereótipos.

\subsection{Comunidade Caboclos do Assu}

A Comunidade Caboclos do Assu está localizada na região oeste potiguar, às margens da RN 233, a aproximadamente $15 \mathrm{~km}$ da zona urbana do município de Assu-RN, e tem população estimada em 100 
pessoas e em cerca de 40 famílias. Os animais típicos da caatinga também estão presentes na comunidade. Porém, devido à existência de diversas agroindústrias nas proximidades, ao desmatamento e outras atividades antrópicas têm reduzido de forma significativa a fauna local (LOPES, 2017).

Dentre as principais fontes de geração de renda, os homens em idade produtiva frequentemente trabalham em empresas regionais de fruticultura. Atualmente, a produção artesanal se limita a vassouras e bolsa de palha, feitos por uma moradora, mas já foram desenvolvidos outros itens (LOPES, 2017).

Em relação aos programas sociais governamentais de distribuição de renda, alguns são beneficiários do programa Bolsa Família, mas segundo relatos a renda não agrícola mais expressiva é a aposentadoria: "nunca recebi isso, mas tem muitos que têm e eu agradeço muito por todos, eu só tenho meu aposento"; "as pessoas trabalham nessa firma de banana, outros vai trabalhar fora, só os homens"; "aqui, quem não é aposentado, vai trabalhar fora do Assu, pra Ipanguaçu”.

A dependência do trabalho externo nas empresas agrícolas de médio e grande porte se deve historicamente aos latifúndios formados pela disputa por terras. Os Caboclos do Assu estão há pelo menos seis gerações dependendo da oferta de trabalho das agroindústrias e fazendas (OLIVEIRA, 2014). Nas terras que restaram, desenvolvem agricultura de sequeiro, com fins de subsistência e a produção de animais como bovinos, ovelhas, cabras e galinhas, também para consumo familiar (LOPES, 2017).

A comprovação da expulsão dos indígenas de suas terras, por parte daqueles que se diziam donos é evidente em relatos de moradores: “as terras eram apropriadas 'no grito' e se convencia os moradores locais a se tornarem empregados", persuadidos pelo poder econômico dos fazendeiros. "Aqui somos meeiros e precisamos de autorização do fazendeiro até para pescar no açude".

As dificuldades locais ficam explícitas no depoimento de uma moradora: "aqui sofreram e sofreram muito, passar quatro ou cinco anos de seca, deixar a família morta de precisão dentro de casa, muitos 
dias forrar o chão com uma esteirinha velha pra se deitar mãe e filho, porque não tinha um cobertor pra se cobrir".

Em termos de infraestrutura, a comunidade não dispõe de escola local. Por isso, as crianças são deslocadas em carro disponibilizado pela Prefeitura para escolas em Assu-RN, Paraú-RN e na comunidade vizinha Riacho, onde estudam a Língua Portuguesa e não há ensino de Língua Indígena. Grande parte das residências é de taipa. A Associação Comunitária de Caboclos do Assu ainda não tem sede própria. Quinzenalmente são assistidos pela Equipe Multidisciplinar de Saúde Indígena da Secretaria Especial de Saúde Indígena - SESAI do Ministério da Saúde. Por falta de local próprio, o atendimento médico e os encontros da associação são realizados na residência do Cacique Adriano (LOPES, 2017).

De etnia potiguara, os indígenas da Comunidade Caboclos do Assu estão em um nível mais incipiente de desenvolvimento quando comparada à Comunidade do Amarelão. Ainda assim, há a possibilidade de realizar ações voltadas para o etnoturismo como forma de valorização e resgate histórico-cultural e geração de renda.

\subsection{Atrativos naturais e socioculturais}

Em relação aos principais atrativos naturais e socioculturais locais, um destaque é o "Açude do Riacho" (Figura 4), utilizado para pesca e sedentização animal, principalmente das ovelhas. O local também é espaço de lazer para moradores e visitantes.

A vegetação nativa (Figura 5) expressa a diversidade da caatinga, com a presença especialmente de pereiro, jurema, mufumbo, juazeiro, cactos, mandacaru e bromélias. Dentre os artefatos antigos, alguns moradores dispõem de ferro de passar roupa a carvão, pilão para pilar arroz e esteira de palha. 
Figura 4-Açude do riacho

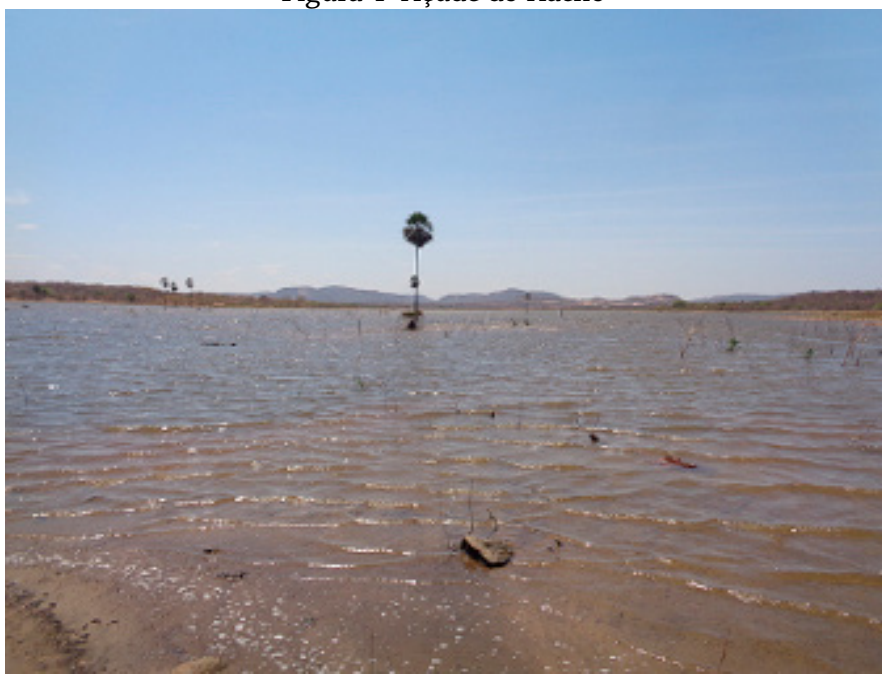

Fonte: Martins (2018).

Figura 5-Vegetação nativa

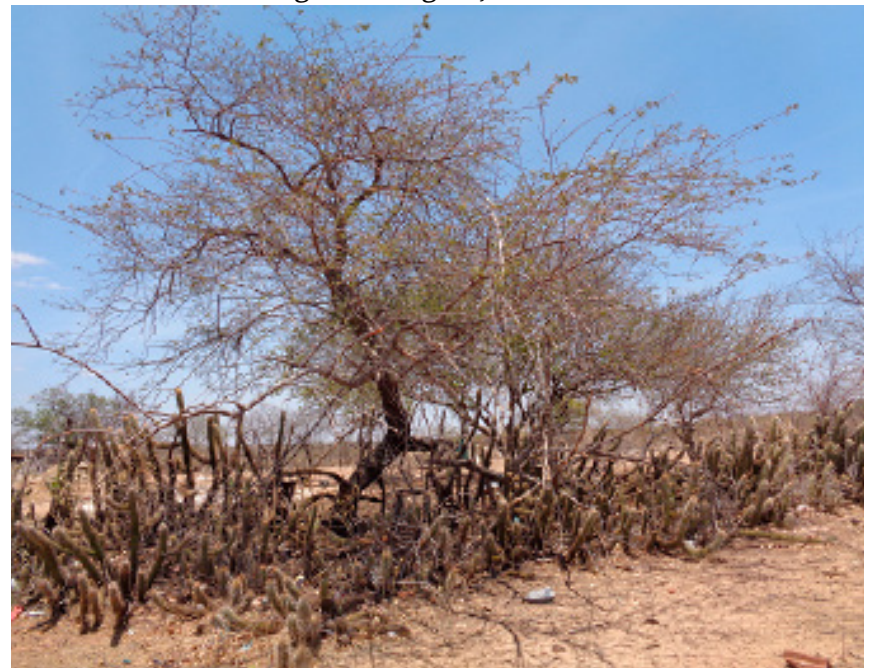

Fonte: Martins (2018). 
É importante salientar que a maior riqueza do local está nas vidas humanas. A exemplo dos irmãos "Zamba", Sr. Antônio Luis Lopes e "Bolero", Sr. Antônio Francisco da Silva, ambos septuagenários. Pessoas experientes e bastante conhecedoras da trajetória da etnia na região e que repassam seus conhecimentos através da história oral para as atuais gerações.

Diante das possibilidades apresentadas de desenvolvimento de etnoturismo nestas comunidades, é necessário destacar o limiar entre o turismo predatório e o turismo responsável, para que a gestão não sofra intervenção meramente exploratória de agências de turismo, mas que seja de base comunitária, na qual exista responsabilidade social e preocupação com a preservação ambiental e costumes étnicos (PEREIRO, 2013).

Nesse contexto é fundamental, para além da autoafirmação, a demarcação das terras indígenas no Rio Grande do Norte para que as comunidades possam com autonomia se empoderar dos próprios rumos e traçar estratégias sustentáveis, com o apoio institucional do Estado.

\subsection{Considerações finais}

As comunidades indígenas Mendonça do Amarelão (João Câmara$\mathrm{RN}$ ) e Caboclos do Assu (Assu-RN) têm potencialidades de geração de renda não agrícola. Dentre elas, o etnoturismo se configura como uma possibilidade. Embora a literatura destaque as limitações desse tipo de intervenção, é fundamental assegurar a sustentabilidade socioambiental e econômica por meio da gestão de base comunitária.

A Comunidade Mendonça do Amarelão apresenta condições relativamente favoráveis para o desenvolvimento do etnoturismo, com ênfase na anual festa da castanha, a trilha aos pontos de memória, o artesanato, a culinária e a riqueza cultural do seu povo. $\mathrm{Na}$ Comunidade Caboclos do Assu, o processo ainda se encontra bastante incipiente e a possibilidade etnoturística requer maior apoio de organizações governamentais e não governamentais. 
Embora as comunidades tenham diferentes contextos e infraestrutura, as lideranças locais demonstram interesse em desenvolver atividades voltadas para o turismo, como uma das possibilidades de afirmação cultural e de geração de renda.

As populações das comunidades autoidentificadas indígenas já sofreram bastante impacto no processo histórico de aculturação e perda territorial e, nesse momento de autoafirmação, resgate cultural e luta territorial é preciso ter domínio sobre os rumos que se quer tomar, inclusive em projetos de cunho econômico. Por isso, a preocupação de que a intervenção exógena interfira no tipo de turismo desenvolvido. Daí a necessidade de implementação de políticas públicas que viabilizem projetos sustentáveis.

É importante ressaltar ainda que a sustentabilidade das comunidades depende da fundamental e necessária demarcação das terras indígenas no Estado, uma vez que o reconhecimento oficial é a forma mais digna de devolver aos povos indígenas a condição de herdeiros de suas terras. Assim, com o resgate da história e a valorização da cultura e do meio ambiente, o apoio às atividades produtivas sustentáveis e às práticas não agrícolas como o artesanato e o etnoturismo irão acontecer de forma mais sistemática e a sociedade como um todo sairá ganhando.

\subsection{Agradecimentos}

Às lideranças e demais informantes das comunidades autoidentificadas indígenas, pelas valiosas informações.

À Universidade Federal Rural do Semi-Árido - UFERSA e ao Conselho Nacional de Desenvolvimento Científico e Tecnológico - CNPq, pela concessão de bolsa a estudante por meio do Programa Institucional de Bolsas de Iniciação Científica (PIBIC/UFERSA/CNPq), via Edital IC no 10/2017 - PROPPG (Pró-Reitoria de Pesquisa e Pós-Graduação). 


\section{REFERÊNCIAS}

\section{ASSOCIAÇÃO COMUNITÁRIA DO AMARELÃO-ACA. Censo}

Comunitário do Amarelão 2018. João Câmara: ACA, 2018. 41 p.

ASSOCIAÇÃO NACIONAL DE AÇÃO INDIGENISTA - ANAÍ. Povos Indígenas: Regiões Nordeste-Leste. [S.l.:s.n.], 2020. Disponível: http://anai.org.br/\#indig_screen. Acesso: 17 maio 2018.

BOFF. L. Sustentabilidade: o que é o que não é. Petrópolis, RJ: Vozes, 2012.

BRASIL. Fundação Nacional do Índio. Instrução Normativa $n^{\circ}$ 03/2015, de 11 de junho de 2015. Estabelece normas e diretrizes relativas às atividades de visitação para fins turísticos em terras indígenas. Diário Oficial da União: seção 1, Brasília, DF, n. 110, 12 jun. 2015. Disponível em: https://bit.ly/2DKLauK. Acesso: 19 ago. 2018.

BRASIL. Fundação Nacional do Índio. PNGATI: instrumentos. Brasília: FUNAI, 2020. Disponível em: http://cggamgati.funai.gov.br/ index.php/pngati/instrumentos. Acesso: 29 out. 2019.

BRASIL. Fundação Nacional do Índio. Terras indígenas. Brasília: FUNAI, 2019. Disponível em: http://www.funai.gov.br/index.php/indios-nobrasil/terras-indigenas. Acesso: $14 \mathrm{dez} .2019$. 
BRASIL. Fundação Nacional do Índio. Mapas. Brasília: FUNAI, 2018. Disponível: http://www.funai.gov.br/index.php/servicos/ geoprocessamento. Acesso: 16 ago. 2018.

BRASIL. Casa Civil. Decreto no 7.747/2012, de 5 de junho de 2012. Institui a Política Nacional de Gestão Territorial e Ambiental de Terras Indígenas-PNGATI, e dá outras providências. Diário Oficial da União, Brasília, DF, 5 jun. 2012. Disponível em: https://bit. ly/3eGc57T. Acesso em: 19 ago. 2018.

CARVALHO, J. J. 'Espetacularização' e 'canibalização' das culturas populares na América Latina. Revista Anthropológicas, v. 21, n. 1, 2010. Disponível em: https://bit.ly/3eEqD82. Acesso em: 15 abr. 2019.

CONSELHO INDIGENISTA MISSIONÁRIO-CIMI. Reivindicada desde 2005, Funai começa trabalho de demarcação no RN. Brasília: CIMI, 2011. Disponível em: https://cimi.org.br/2011/07/32322/. Acesso em: 15 nov. 2019.

\section{CONSELHO INDIGENISTA MISSIONÁRIO-CIMI. Relatório} violência contra os povos indígenas no Brasil: dados de 2016. Brasília: CIMI, 2016, 152 p. Disponível em: https://bit.ly/2Cpc7E7. Acesso em: 25 nov. 2019.

FARIA, I. F. Ecoturismo: etnodesenvolvimento e inclusão social no Amazonas. Revista de Turismo y Patrimonio Cultural, v. 3, n. 1, p. 63-77, 2005. Disponível em: https://bit.ly/2ZCpZn3. Acesso em: 3 set. 2019.

FELIX, J. P. S; FARIAS, M. F.; CHAGAS, M. M; MARQUES JÚNIOR, $S$. Turismo de base local e cultura: uma análise da relação entre o apoio ao turismo e seus antecedentes em comunidades indígenas e quilombolas no Rio Grande do Norte (Brasil). RTEP-Revista 
Turismo estudos \& práticas, v. 9, n. 1. p. 1-25, 2020. Disponível em: https://bit.ly/3hdIyEn. Acesso em: 3 maio 2020.

FORTUNATO, R. A. Os significados do turismo comunitário indígena sob a perspectiva do desenvolvimento local: o caso da reserva de desenvolvimento sustentável do Tupé-AM. CULTURRevista de Cultura e Turismo, v. 5, n. 2, p. 85-100, 2011. Disponível: https://periodicos.uesc.br/index.php/cultur/article/view/382. Acesso em: 3 maio 2019.

\section{FREITAS, M. M. Relatos sobre o massacre de 70 índios na}

Serra de Portalegre/RN: argumentação em discursos de liderança indígena e alunos do ensino fundamental. 2018. 295 f. Dissertação (Mestrado Profissional em Letras) - Universidade do Estado do Rio Grande do Norte, Pau dos Ferros, 2018. Disponível em: https://bit. ly/2ClzeiQ. Acesso em: 3 nov. 2019.

GONZÁLEZ, M. M. ¿Etnoturismo o turismo indígena? Teoría Y Praxis, n. 5, p. 123-136, 2008. Disponível em: https://dialnet.unirioja. es/servlet/articulo?codigo=2929496. Acesso em: 7 nov. 2019.

GUERRA, J. G. A. Mendonça do Amarelão: origem, migrações, aspectos de sua cultura e identidade étnica. João Pessoa: Ideia, 2017. (Coleção Matiapoa, v. 1).

INSTITUTO BRASILEIRO DE GEOGRAFIA E ESTATÍSTICA-IBGE. Mapas IBGE: Rio Grande do Norte. Rio de Janeiro: IBGE, 2017. Disponível em: https://mapas.ibge.gov.br. Acesso em: 04 maio 2018.

INSTITUTO BRASILEIRO DE GEOGRAFIA E ESTATÍSTICAIBGE. Os indígenas no Censo Demográfico 2010: primeiras considerações com base no quesito cor ou raça. Rio de Janeiro: IBGE, 2010. Trabalho elaborado em comemoração ao Dia do Índio. 2010. Disponível: http://www.ibge.gov.br/indigenas/indigena_censo2010.pdf. Acesso em: 18 nov. 2019. 
INSTITUTO BRASILEIRO DE GEOGRAFIA E ESTATÍSTICA IBGE. Os indígenas no Censo Demográfico 2010: primeiras considerações com base no quesito cor ou raça. Rio de Janeiro: IBGE, 2012. 31 p. Disponível em: https://ibge.gov.br/indigenas/indigena_ censo2010.pdf. Acesso em: 7 nov. 2018.

INSTITUTO SOCIOAMBIENTAL - ISA. Potiguara. [S.l.]: ISA, 2017. Disponível em: https://pib.socioambiental.org/pt/Povo:Potiguara. Acesso em: 7 maio 2018.

LOPES, A. A. Geração de renda, aspectos socioambientais e etno-culturais das comunidades indígenas do semiárido potiguar. [Entrevista cedida a J. C. V. Martins]. Assu, RN, 5 out. 2017.

MACEDO, H. A. M. Populações indígenas no sertão do Rio Grande do Norte: história e mestiçagens. Natal: EDUFRN, 2011.

MEIRELES, A. J. A. Unidades de paisagem na Terra indígena Tremembé de São José e Buriti, Município de Itapipoca-CE. In: SILVA, E. V.; MEIRELES, A. J. A.; GORAYEB, A. (org.) Educação ambiental e indígena: caminhos da extensão universitária na gestão de comunidades tradicionais. Fortaleza: Edições UFC, 2011.

MELO, B. S. Índios do Rio Açu. [S.l.]: Recanto das Letras, 2013. Cordel. Disponível em: https://www.recantodasletras.com.br/ cordel/4299854. Acesso em: 04 jun. 2018.

NORA, P. Entre memória e história: a problemática dos lugares. Tradução de Y. A. KHOURY. Projeto História-Revista do Programa de Estudos Pós-graduados de História. v. 10, 1993. Disponível em: https://revistas.pucsp.br/revph/article/view/12101/8763. Acesso em: 4 abr. 2020. 
OIT-ORGANIZAÇÃO INTERNACIONAL DO TRABALHO Convenção $n^{\circ} 169$ sobre povos indígenas e tribais e Resolução referente à ação da OIT. Brasília: IPHAN, 2011. Disponível em: https://bit.ly/32H8HHl. Acesso em: 21 abr. 2019.

\section{ONU-ORGANIZAÇÃO DAS NAÇÕES UNIDAS. Declaração} sobre os direitos dos povos indígenas. São Paulo: USP, 2007. Disponível em: https://bit.ly/2ZOiv0u. Acesso em: 21 abr. 2019.

OPENBRASIL. Rio Grande do Norte. [S.l.:s.n.], [2018?].

Disponível em: http://riograndedonorte.openbrasil.org. Acesso em: 04 ago. 2018.

OLIVEIRA, J. N. V. Revista de Humanidades: "ser índio" e "ser caboclo" potiguar: história indígena e o processo identitário nas comunidades dos caboclos do Assu. v. 15, n. 35, p. 191-197, 2014. Disponível em: https://periodicos.ufrn.br/mneme/article/view/7819. Acesso em: 16 maio 2018.

OLIVEIRA, J. P. Uma etnologia dos "índios misturados"? situação colonial, territorialização e fluxos culturais. Mana, Rio de Janeiro, v. 4, n. 1, p. 47-77, abr. 1998. Disponível em: https://bit.ly/3g0aD1q. Acesso em: 24 nov. 2018.

PEREIRO, X. Los efectos del turismo en las culturas indígenas de América Latina. Revista Española de Antropología Americana, v. 43, n. 1, p. 155-174, 2013. Disponível em: http://revistas.ucm.es/ index.php/REAA/article/download/42308. Acesso em: 01 maio 2018.

RELATÓRIO final. In: ASSEMBLEIA DOS POVOS INDÍGENAS DO RIO GRANDE DO NORTE, 2., 2011, Goianinha. Relatório [...]. Goianinha: Casa de Cultura Popular Palácio Antônio Bento, 2011. 
SILVA, E. V.; MEIRELES, A. J. A.; GORAYEB, A. (org.) Educação ambiental e indígena: caminhos da extensão universitária na gestão de comunidades tradicionais. Fortaleza: Edições UFC, 2011.

SILVA, M. I. S. Geração de renda, aspectos socioambientais e etno-culturais das comunidades indígenas do semiárido potiguar. [Entrevista cedida a J. C. V. Martins]. João Câmara, RN, 02 out. 2017.

SILVA, M. E. C; LOPES, J. B.; BARROS, R. F. M.; ALENCAR, N. L.; MENDES, L. M. S. A etnoconservação no contexto da agrobiodiversidade: diálogos entre os saberes científicos e locais em tempos de crise ambiental. Espacios, v. 37, n. 37, 2016. Disponível em: http://www.revistaespacios.com/a16v37n37/16373703.html. Acesso em: 30 set. 2018.

SOUZA, E. P.; MARTINS, S. R. O.; ARAÚJO, A. P. C. Fronteira etnocultural e desenvolvimento rural: o produto turístico "trem do pantanal” no distrito de Taunay. ACTA Geográfica, v. 5, n. 10, jul./dez. 2011. p. 37-53. Disponível em: https://bit.ly/3eSBfz. Acesso em: 1 maio 2018.

VIEIRA, J. G.; KÓS, C. Invisibilidade, resistência e reconhecimento. In: RICARDO, B.; RICARDO, F. Povos Indígenas do Brasil 2011/2016. São Paulo: Instituto Socioambiental, 2017. p. 519-522. 